\title{
Boric Acid Production from a Low-Grade Boron Ore with Kinetic Considerations
}

\author{
Mahdi $\mathbf{H}^{1^{*}}$, Davood $\mathbf{M}^{2}$, Mohsen $\mathbf{V}^{3}$ and Behzad $\mathbf{S}^{3}$ \\ ${ }^{1}$ College of Engineering, University of Tehran, Tehran, Iran \\ ${ }^{2}$ Faculty of Engineering, University of Zanjan, Zanjan, Iran \\ ${ }^{3}$ Research and Engineering Company for Non-Ferrous Metals, Zanjan, Iran
}

\begin{abstract}
The most important Iranian boron reserves are in the basin of Ghezel Ozan, a river in the West and Northwest area of Zanjan. In the present study, boric acid production from an Iranian low-grade borate ore by hydrometallurgical process was investigated. In order to produce boric acid, boron ore was reacted with sulphuric acid. The influence of four parameters on the course of reaction such as $\mathrm{pH}$, temperature, liquid to solid ratio, and reaction time was examined. Optimum condition for leaching part was obtained in temperature of $90^{\circ} \mathrm{C}$, reaction time of 2 hours, L/S ratio of 3 , and $\mathrm{pH}$ of 1 . Under these conditions, the recovery of boron acidic leaching was reported to be $92.21 \%$. Neutralization of pulp was done by lime. Finally, boric acid was obtained by crystallization. The purity of produced boric acid was $99.56 \%$. The data obtained from the acidic leaching kinetics indicated that the dissolution of boron ore is fluid film diffusion controlled reaction and the reaction activation energy equals to $11.6 \mathrm{~kJ} / \mathrm{mol}$. Enthalpy of activation $\left([\Delta H)^{\wedge} \ddagger\right)$ and entropy of activation $\left(\left[\Delta S \rrbracket^{\wedge} \ddagger\right)\right.$ were $11.2 \mathrm{~kJ} / \mathrm{mol}$ and $-246.3 \mathrm{~J} /(\mathrm{mol} . \mathrm{K})$ respectively.
\end{abstract}

Keywords: Boron ore; Optimization; Boric acid; Kinetics

\section{Introduction}

Boron is one of the most significant industrial elements. The total world boron ore reserves are estimated to be equivalent to 885 billion tons [1]. The major boron producers are Turkey (39\% of global production), USA (24\%), Argentina (14\%), and Chile (10\%) [2]. One of the most-used and commercially important boron compounds is boric acid. Due to increasing demands for the boron compounds, especially boric acid which is used in many branches of industry, such as in the medical, pharmaceutical and electronic sectors, the production of these compounds has enhanced recently [3]. Boric acid $\left(\mathrm{H}_{3} \mathrm{BO}_{3}\right)$ can be produced from different boron minerals such as colemanite, tincal, kernite, ulexite or from the brines having dissolved boron salts [4]. Boron compounds found in nature in the form chiefly as calcium, magnesium and sodium borate. In Ca Borate ores, concentration is generally carried out by disintegration, washing and classification in the size fractions in large sizes. Concentrate is obtained through attrition tumbling and hand sorting. In $\mathrm{Na}$ Borate ores, attrition scrubbing to the ore is followed by classification by the use of screens and cyclone. All the water is kept at near saturation with boron since $\mathrm{Na}$ borate is soluble in water [5]. Magnesium borates occur in small quantities in various boron deposits of the world. Commercial Hydroboracite deposits are found in Inder, a place in Siberia. Hydroboracite in Turkey occurs in the Büyük Günevi mine of the Yakal Borasit Ltd [6]. In some boric acid processes, borax is reacted with aqueous hydrochloric acid or nitric acid $[7,8]$. The production cost is very high in this method due to the use of strong acids, which lead to a short life of the equipment. In Europe, boric acid is industrially produced based on the reaction of colemanite with sulphuric acid at $90^{\circ} \mathrm{C}$ [9]. Tunc and Kocakerim investigated the leaching of ulexite in sulphuric acid. The parameters were temperature, particle size, solid-to-liquid ratio, acid concentration, and stirring rate. The results showed that temperature and stirring rate had positive effect on the leaching process. Conversion rate increased with the acid concentration up to $1 \mathrm{~mol} \mathrm{~L}^{-1}$ and decreased with the concentrations above $1 \mathrm{~mol} \mathrm{~L}^{-1}$ [10]. The effect of sulphuric acid concentration on the dissolution of impurities from colemanite was studied by Kalafatoğlu et al. Results demonstrated that if the acid concentration was held around $5 \%$, the dissolution of clay and the other impurities would decrease [11]. In another paper, the crystallization kinetics of gypsum during the dissolution of colemanite in a batch reactor at different temperatures were studied; $\left(60-90^{\circ} \mathrm{C}\right.$, stirring rate: $\left.150-400 \mathrm{rpm}\right)$, and the initial concentration of the reactants. It was found that the crystal growth of gypsum on seed crystals follows a second order kinetics from the solution supersaturated in calcium and sulphate ions [12]. Another study examined the effect of particle size of colemanite on gypsum crystallization in batch reactor [13]. Dissolution kinetics of colemanite in sulphuric acid in the absence and presence of ultrasound was studied by Okur et al. [14]. An Avrami-type equation was used successfully to explain kinetic data. Activation energy was $30 \mathrm{~kJ} / \mathrm{mol}$ in both situations. Iran is one of the countries that have boron mines. There are less than 5 active boron mines in Iran. The most important Iranian boron reserves are in the basin of Ghezel Ozan, a river in the West and North-west area of Zanjan, the North-western region of Iran. Moshampa borate ore containing the minerals, hydroboracite $\left(\left(\mathrm{CaMgB}_{6} \mathrm{O}_{11} .6 \mathrm{H}_{2} \mathrm{O}\right) 90.9 \%\right.$ of all valuable mineral), and pandermite $\left(\mathrm{Ca}_{4} \mathrm{~B}_{10} \mathrm{O}_{19} \cdot 7 \mathrm{H}_{2} \mathrm{O}\right)$ is located in the northwest of Zanjan. The first utilization of this mine started in 2005. This mine being extracted in a non-advanced way. Hence, the objectives of this study were to investigate the main factors involved in the leaching of boron ore by sulphuric acid solution, such as solid/ liquid ratio, temperature, $\mathrm{pH}$ and time, and also to determine what processes control the rate of the dissolution of boron ore or what kinetic model can be applied.

\section{Materials and Methods}

\section{Materials}

The sample under the study was obtained from damp of Moshampa boron mine, Zanjan, Iran. Prior to this study, the boron ore sample was dried, grounded, and homogenized. The chemical analysis was carried out with a Spectro XEPOS model XRF, as well as boron content by inductively coupled plasma-atomic emission spectrometry (ICP-AES)

*Corresponding author: Mahdi $\mathrm{H}$, College of Engineering, University of Tehran, Tehran, Iran, Tel: 989195249276; E-mail: haghani.mahdi@ut.ac.ir

Received April 29, 2016; Accepted May 17, 2016; Published May 22, 2017

Citation: Mahdi H, Davood M, Mohsen V, Behzad S (2017) Boric Acid Production from a Low-Grade Boron Ore with Kinetic Considerations. Mod Chem appl 5: 218. doi: 10.4172/2329-6798.1000218

Copyright: (C) 2017 Mahdi $\mathrm{H}$. This is an open-access article distributed under the terms of the Creative Commons Attribution License, which permits unrestricted use, distribution, and reproduction in any medium, provided the original author and source are credited. 
Citation: Mahdi H, Davood M, Mohsen V, Behzad S (2017) Boric Acid Production from a Low-Grade Boron Ore with Kinetic Considerations. Mod Chem appl 5: 218. doi: 10.4172/2329-6798.1000218

method. The chemical analysis of the boron ore is given in Table 1. As can be seen from Table 1, studied sample is mostly composed of B and $\mathrm{Ca}$. Furthermore, the characterization of minerals in the boron ore was performed by X-ray powder diffraction (XRD) under the condition of $\mathrm{Cu} \mathrm{Ka}$ at $40 \mathrm{kV}$ and $30 \mathrm{~mA}$ as shown in the Figure 1. The results of $\mathrm{XRD}$ analysis revealed that $\mathrm{CaSO}_{4} \cdot 2 \mathrm{H}_{2} \mathrm{O}$ and $\mathrm{CaCO}_{3}$, were the major, $\mathrm{Ca}_{4} \mathrm{~B}_{10} \mathrm{O}_{19} \cdot 7 \mathrm{H}_{2} \mathrm{O}$ (pandermite) and $\mathrm{CaMgB}_{6} \mathrm{O}_{11} \cdot 6 \mathrm{H}_{2} \mathrm{O}$ (Hydroboracite) were the minor mineralogical phases in Moshampa boron ore. SEM of the boron ore were performed by Scanning Electronic Microscope model XL-30 which was manufactured by Philips. The SEM image of boron ore (Figure 2) showed that they consist of large sheet form particles, sized less than $100 \mu \mathrm{m}$. In the leaching experiments, sulphuric acid was used which made by Merck with a purity of $98 \%$ and a density of $1.89 \mathrm{~g} / \mathrm{mL}$. Acidic leach of boron was examined in four parameters of $\mathrm{pH}$, temperature, liquid to solid ratio, and reaction time. For each parameter, four levels were chosen as shown in Table 2.

\section{Methods}

Boric acid production took place in a glass beaker of 5 Littre volume, equipped with a mechanical stirrer submerged in a thermostatic bath. The mechanical stirrer (Heidolf RZR 2020) had a controller unit and the bath temperature was controlled using thermometer (within \pm $0.5^{\circ} \mathrm{C}$ ). Leaching experiments were performed based on our previous experience in related works and preliminary tests. Time, temperature, $\mathrm{pH}$, and $\mathrm{L} / \mathrm{S}$ amount were chosen as the four variables to be investigated. For each experimental condition, the experiment was repeated twice, and the arithmetic average of the results was used in the plotting of yield curves. The ranges and values of parameters for leaching tests are given in Table 2. After adding acid to the reaction beaker and setting the temperature at the desired value, a known weight of sample was added to the reactor while the content of the reactor was stirred at a certain speed $(700 \mathrm{rpm}) . \mathrm{pH}$ was adjusted by adding drops of concentrated sulphuric acid (98\%). Under desired circumstance, $\mathrm{B}_{2} \mathrm{O}_{3}$ was absorbed in the solution phase. In the next step, impurities of ' $\mathrm{Fe}$ ' were precipitated using lime as iron hydroxide in $\mathrm{pH}$ of 5 . Obtained filtrate in this part was crystallized by reducing the temperature and eventually boric acid was produced. Optimization was carried out in classic method, similar to the mineral processing part.

\section{Results and Discussion}

\section{Investigation of effective parameters in acidic leaching}

Equations 1 and 2 present the dissolution of boron in acid reactions. Thermodynamic data showed that the dissolution of boron in sulfuric acid occurs due to Eq. (1) and 2, which is calculated with HSC 5.1 software. The Eh-pH diagrams for the B-S-water system at the temperature of $90^{\circ} \mathrm{C}$, as seen in Figure 3, illustrates at $90^{\circ} \mathrm{C}$, the lines related to the specie of $\mathrm{H}_{3} \mathrm{BO}_{3}$ is the stable type of reaction's yield.

\begin{tabular}{|c|c|c|c|c|c|c|c|}
\hline \multicolumn{7}{|c|}{ Content [wt. \%] } \\
\hline $\mathbf{B}_{2} \mathbf{O}_{3}$ & $\mathbf{C a O}$ & $\mathbf{M g O}$ & $\mathrm{SiO}_{2}$ & $\mathrm{Fe}_{2} \mathbf{O}_{3}$ & $\mathbf{A l}_{2} \mathrm{O}_{3}$ & $\mathbf{K}_{2} \mathrm{O}$ & $\mathbf{N a}_{2} \mathbf{O}$ \\
\hline 8.95 & 29.59 & 3.51 & 5.29 & 0.92 & 0.89 & 0.19 & 5.03 \\
\hline
\end{tabular}

Table 1: Chemical analysis of the boron ore.

\begin{tabular}{|c|c|c|c|c|c|}
\hline Parameters & Units & Level 1 & Level 2 & Level 3 & Level 4 \\
\hline $\mathrm{pH}$ & - & 1 & 1.5 & 1.75 & 2 \\
\hline Temperature & ${ }^{\circ} \mathrm{C}$ & $50^{*}$ & 70 & 80 & 90 \\
\hline $\mathrm{L} / \mathrm{S}$ & $\mathrm{L} / \mathrm{kg}$ & $1.5^{*}$ & 2 & 3 & 5 \\
\hline Time & $\mathrm{min}$ & $30^{*}$ & 60 & 90 & 120 \\
\hline
\end{tabular}

*Base level of each parameter

Table 2: Special parameters in precipitation of Lead with Zinc powder.

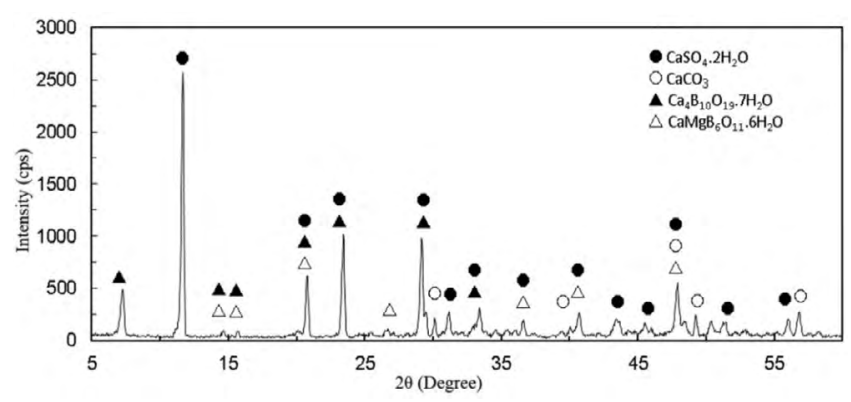

Figure 1: XRD analysis of the boron ore.

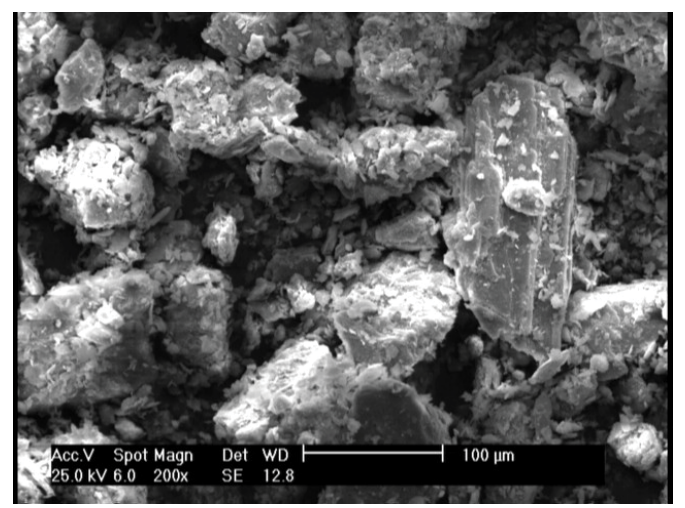

Figure 2: SEM analysis of the boron ore.

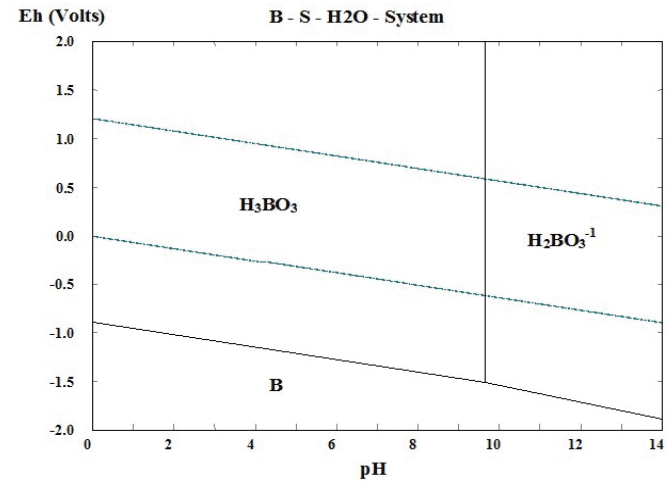

Figure 3: Eh-pH diagrams for the B-S-water system at the temperature of $90^{\circ} \mathrm{C}$.

$$
4 \mathrm{CaO}+3 \mathrm{~B}_{2} \mathrm{O}_{3}+4 \mathrm{H}_{2} \mathrm{SO}_{4}+7 \mathrm{H}_{2} \mathrm{O} \leftrightarrow 4 \mathrm{CaSO}_{4}+6 \mathrm{H}_{3} \mathrm{BO}_{3}+2 \mathrm{H}_{2} \mathrm{O}
$$

$\Delta \mathrm{G}$ of $-1145.79 \mathrm{~kJ} / \mathrm{mol}$ at $90^{\circ} \mathrm{C}$

$\mathrm{CaO}+\mathrm{MgO}+3 \mathrm{~B}_{2} \mathrm{O}_{3}+2 \mathrm{H}_{2} \mathrm{SO}_{4}+9 \mathrm{H}_{2} \mathrm{O}$

$$
\leftrightarrow \mathrm{CaSO}_{4}+6 \mathrm{H}_{3} \mathrm{BO}_{3}+\mathrm{MgSO}_{4}+2 \mathrm{H}_{2} \mathrm{O}
$$

$\Delta \mathrm{G}$ of $-493.21 \mathrm{~kJ} / \mathrm{mol}$ at $90^{\circ} \mathrm{C}$

Experiments were carried out to investigate the effect of $\mathrm{pH}$ on the dissolution of boron under constant conditions of temperature of $50^{\circ} \mathrm{C}$, $\mathrm{L} / \mathrm{S}$ ratio of 1.5 , and reaction time of $30 \mathrm{~min}$. Increasing the dissolution of boron resulted in an increase in $\mathrm{pH}$. As it can be seen in Figure 4, maximum recovery is in minimum $\mathrm{pH}$. In this $\mathrm{pH}$, the amount of dissolution was $59.71 \%$. Therefore, to investigate the other parameters, the $\mathrm{pH}$ of 1 was chosen as the optimum $\mathrm{pH}$. Figure 5 shows the effect of temperature on the boron leaching. As it was shown in Figure 5, the maximum dissolution of boron was noticed in the temperature of 


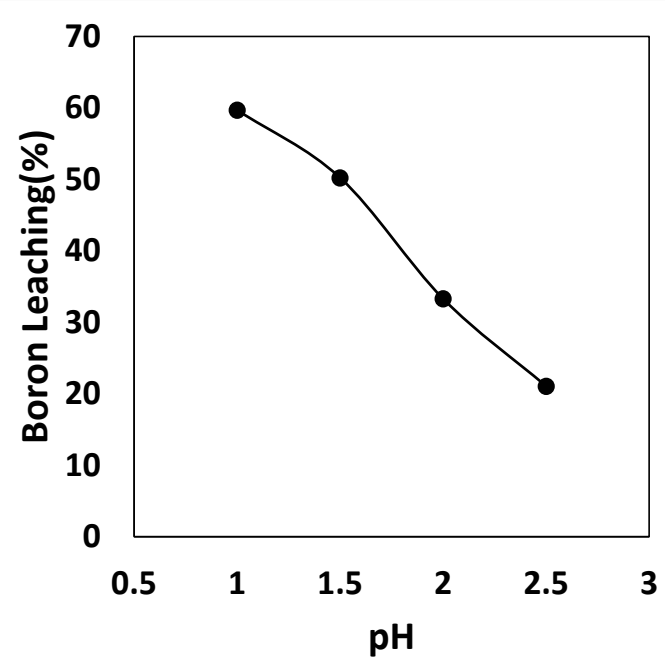

Figure 4: Effect of $\mathrm{pH}$ on boron leaching (temperature: $50^{\circ} \mathrm{C}$; time: $30 \mathrm{~min}$, L/S ratio: 1.5$)$.

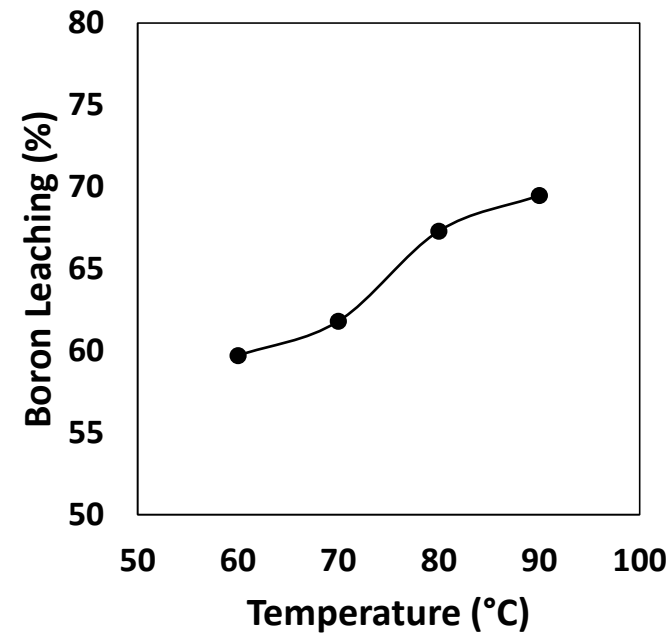

Figure 5: Effect of temperature on boron leaching ( $\mathrm{pH}: 1$; time: $30 \mathrm{~min}$, L/S ratio: 3 ).

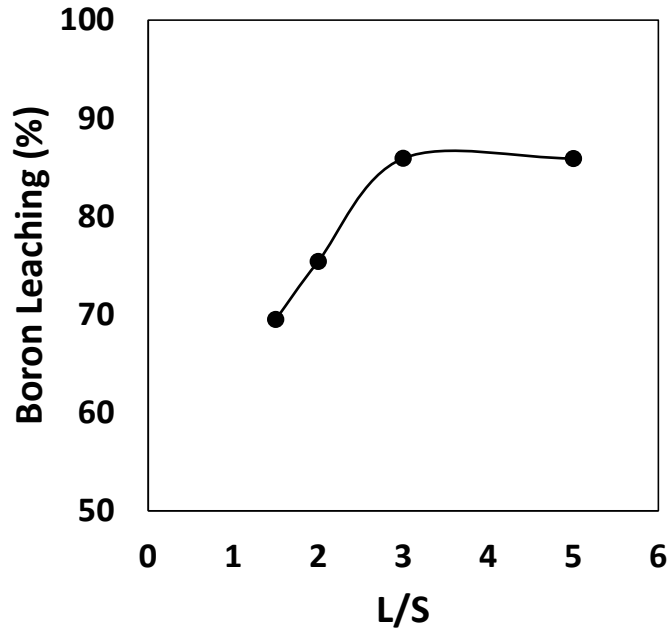

Figure 6: Effect of $\mathrm{L} / \mathrm{S}$ ratio on boron leaching $(\mathrm{pH}: 1$; time: $30 \mathrm{~min}$, temperature: $\left.90^{\circ} \mathrm{C}\right)$. $90^{\circ} \mathrm{C}$ that equaled $69.48 \%$. Constant factors in this experiment were as follows: $\mathrm{pH}$ of $1, \mathrm{~L} / \mathrm{S}$ ratio of 1.5 , and reaction time of $30 \mathrm{~min}$. Figure 6 shows the effect of liquid on solid ratio on the boron leaching. As it is shown in Figure 6, increasing the L/S ratio up to 3 resulted in an increase in boron leaching amount, $85.91 \%$. Increasing of L/S ratio to more than 3 does not show significant change in solubility of boron. Constant factors in this experiment were as follows: $\mathrm{pH}$ of 1 , temperature of $90^{\circ} \mathrm{C}$, and reaction time of $30 \mathrm{~min}$. The reaction time was the last factor which was tested. As it is shown in Figure 7, the optimal mode for dissolution was $92.21 \%$, at the time of $120 \mathrm{~min}$. Constant factors in this experiment were as follows: $\mathrm{pH}$ of 1 , temperature of $90^{\circ} \mathrm{C}$, and $\mathrm{L} / \mathrm{S}$ ratio of 3 .

\section{Kinetic modelling}

For the kinetics study, the experiment was conducted in the optimum condition achieved by design of experiment software and central composite method. The sample of the solution was taken between determined time intervals. As it is shown in Figure 8, efficiency of acidic leaching increased sharply during the first 30 minutes. Information on times higher than the 30 minutes was excluded in kinetic study due to low growth rate of efficiency. In chemical and hydrometallurgical processes fluid-solid reaction rate maybe generally controlled by one of the following steps: diffusion through fluid film, diffusion through ash or the chemical reaction at the surface of the core or unreacted materials in the solid liquid systems [15]. The rate of the process is controlled by the slowest of the sequential steps. As the reaction of Boron particles precede, the thickness of outer shell of insoluble product progressively increased while the inner core of unreacted particle decreased. It is clear from Figure 9 that the rate of reaction increases with time. This is due to the growth of the reactant surface and the increase in path length for the diffusion of ions $[16,17]$.

\section{Chemical reaction rate controlling system}

The fraction of Boron reacted at any time, $t$, in a reaction control process can be calculated from the following equation [15]: where $\mathrm{XB}$ is the fraction of Boron reacted. The time for complete disappearance of a particle, $\tau$, can be calculated from:

$$
\mathrm{t} / \tau=1-(1-\mathrm{XB}) 1 / 3
$$

$$
\text { where } \tau=(\rho \text { R0 }) /(\text { b KS C) }
$$

where $\rho$ is density of Boron ore, R0 is radius of the unreacted particle, $b$ is stoichiometric coefficient of the reaction, $\mathrm{C}$ is concentration of sulphuric, and KS is rate constant of the reaction. Based on the experimental data plotted in Figure 10, the right-hand side of Eq. (3) is plotted against reaction time in Figure 8. It is obvious that the data do not fit with a straight line and it is concluded that the chemical reaction could not be rate determining in the leaching system used here.

\section{Solid product diffusion control}

Diffusion of the reagent or dissolved species through a solid reaction product at any time, $\mathrm{t}$, can be calculated from the following equation [15]:

$$
\mathrm{t} / \tau=1-3(1-\mathrm{XB}) 2 / 3+2(1-\mathrm{XB})
$$

In order to test the possibility of diffusion through a solid reaction product, the right-hand side of Eq. (4) is plotted against time and is shown in Figure 11. This is also evident from the high R2 values for film diffusion model as shown in Table 3, which also lists the values of apparent rate constants for Boron with their equivalent correlation coefficients. The kinetic data showed poor fit to the ash diffusion and chemical control model, especially at higher temperatures. Therefore, the data can be correlated with diffusion through fluid film. 


\section{Activation energy}

The temperature dependence of the reaction rate constant can be calculated by the Arrhenius equation:

$$
\mathrm{Ka}=\mathrm{A} \exp (-\mathrm{Ea} / \mathrm{RT})
$$

where $\mathrm{A}$ is frequency factor, Ea is activation energy of the reaction, $\mathrm{R}$ is universal gas constant, and $\mathrm{T}$ is absolute temperature. The values of Ka at different temperatures can be calculated from the slope of the lines shown in Figure 9 and Eq. (5). The Arrhenius plot (lnKa vs. 1/T), shown in Figure 12, gives an activation energy of $11.6 \mathrm{~kJ} / \mathrm{mol}(2.77$ $\mathrm{kcal} / \mathrm{mol}$ ) for the reaction from the slope of the lines in the temperature range between 333 and $364^{\circ} \mathrm{K}$. The activation energy of a diffusioncontrolled process is characterized to be from 1 to $3 \mathrm{kcal} / \mathrm{mol}$, while for a chemically controlled process it usually is greater than $10 \mathrm{kcal} / \mathrm{mol}$.

According to the linear form of the Eyring-Polanyi equation (Eq. (6)) the values for $\Delta H \ddagger$ and $\Delta S \ddagger$ can be determined from kinetic data obtained from a $\ln \mathrm{k} / \mathrm{T}$ vs. $1 / \mathrm{T}$ plot (Figure 12.1) The Equation is a straight line with negative slope $\left[-\Delta \mathrm{H} \rrbracket \wedge\right.$ ‡/R, and a y-intercept, ln $\mathrm{k} \_\mathrm{B} /$ $\mathrm{h}+\llbracket \Delta \mathrm{S} \rrbracket \rrbracket^{\wedge} / \mathrm{R}$.

$$
\ln \mathrm{k} / \mathrm{T}=\llbracket(-\Delta \mathrm{H}) \rrbracket^{\wedge} \ddagger / \mathrm{R} 1 / \mathrm{T}+\ln \mathrm{k} \_\mathrm{B} / \mathrm{h}+\llbracket \Delta \mathrm{S} \rrbracket^{\wedge} \ddagger / \mathrm{R}
$$

\section{Where:}

$\mathrm{k}=$ reaction rate constant, $\mathrm{T}=$ absolute temperature, $\Delta \mathrm{H} \neq=$ enthalpy of activation, $\mathrm{R}=$ gas constant, $\mathrm{kB}=$ Boltzmann constant, $\mathrm{h}=$ Planck's constant, $\Delta \mathrm{S} \ddagger=$ entropy of activation.

Hence, with a simple calculation enthalpy of activation ( $\left.\llbracket \Delta \mathrm{H} \rrbracket^{\wedge} \ddagger=11.2 \mathrm{~kJ} / \mathrm{mol}\right)$ and entropy of activation $\left(\llbracket \Delta \mathrm{S} \rrbracket^{\wedge} \ddagger=-246.3 \mathrm{~J} /\right.$ $(\mathrm{mol.K}))$ were evaluated.

\section{Characteristic of produced boric acid}

The results of XRD analysis for Boric acid from acidic leaching reaction revealed that boric acid was the major mineralogical phase in the product, as shown in the Figure 13.

Scanning electron microscopy (SEM) was used for a morphological study of Boric acid deposits under the optimum conditions. SEM micrographs of the sample are presented in Figure 14 and shows sheet form structures crystallization.

\section{Working diagram}

The final process of production of boric acid and boron ore is shown in Figure 15. Firstly, process of grinding the ore is done right on mesh generator. In second step, ore is dissolved in acidic condition with $\mathrm{H}_{2} \mathrm{SO}_{4}$ to $\mathrm{pH}=1$ in temperature of $90^{\circ} \mathrm{C}$. After 120 min of acidic leach in Liquid/Solid rate of 3:1, neutralization process is carried out with lime because of precipitation of iron. In the following steps, solidliquid separation operation is required. Solid part of alkaline leaching separation section is deposited as a waste. Filtrate of neutralization separation section is used by crystallization. Finally, solid boric acid is obtained by filtration and drying of crystals to scale up experiments. To scale up the process, $10 \mathrm{Kg}$ of boron ore was used from Moshampa mine in Province of Zanjan, Iran. Process properties, acidic leaching, neutralization, and crystallization efficiencies were obtained, as shown in Table 4. It explains that acidic leaching rate of boron can reach 99.74\%. After precipitation step, 95\% of iron is removed and around $98.5 \%$ of boron can be extracted from the ore since composition of iron precipitate was environmentally safe in the iron precipitation step. The contents of leaching residue were lower than hazardous limits of the

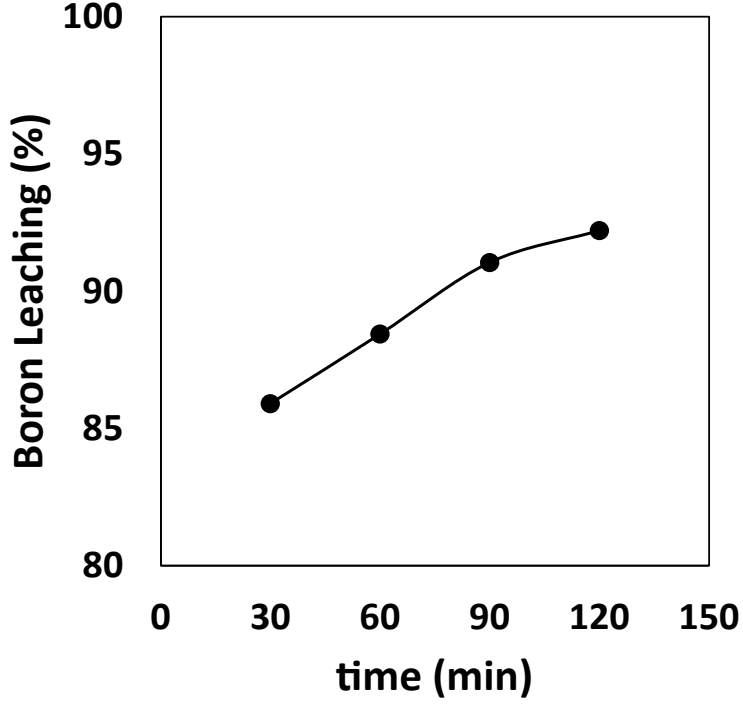

Figure 7: The Effect of reaction time on boron leaching $(\mathrm{pH}: 1 ; \mathrm{L} / \mathrm{S}$ ratio: 3 , temperature: $\left.90^{\circ} \mathrm{C}\right)$

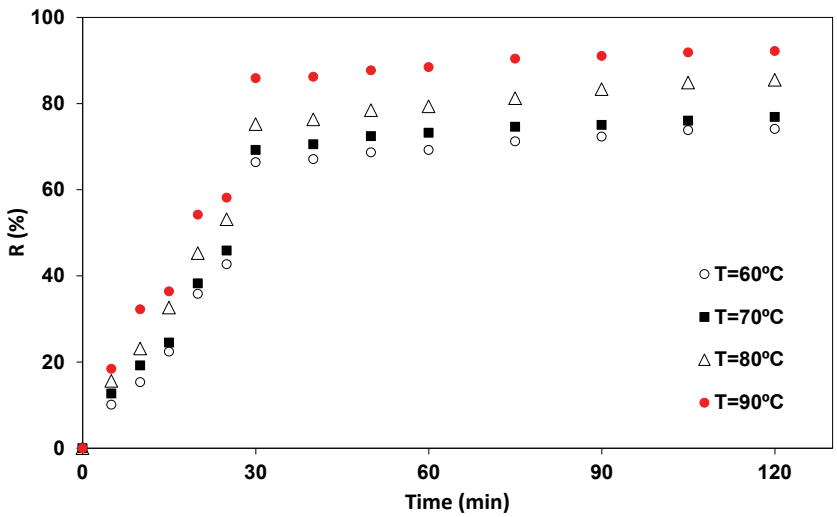

Figure 8: Efficiency of acidic leaching during the time.

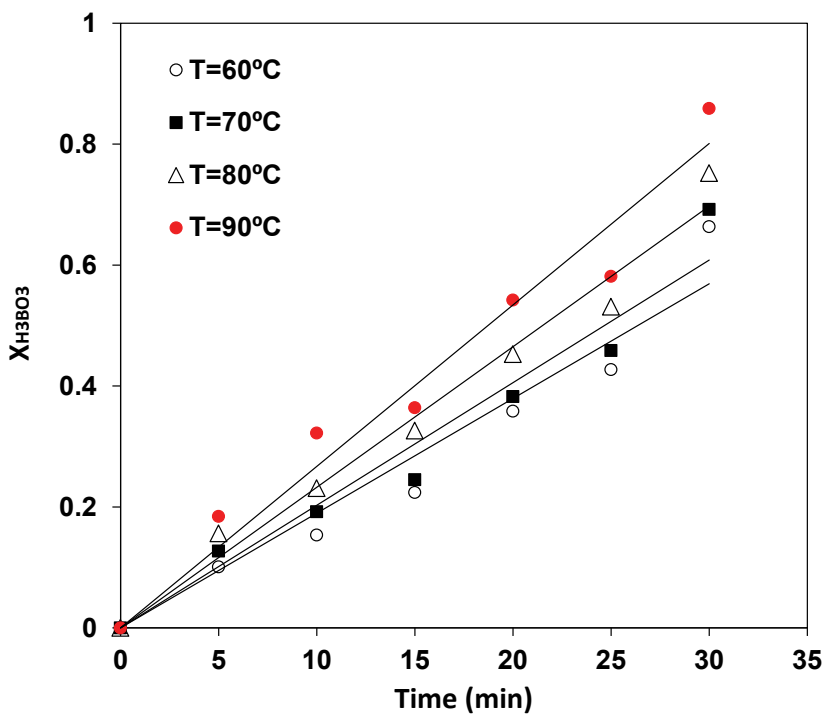

Figure 9: Leaching of Boron with time at various temperatures. 
Citation: Mahdi H, Davood M, Mohsen V, Behzad S (2017) Boric Acid Production from a Low-Grade Boron Ore with Kinetic Considerations. Mod Chem appl 5: 218. doi: 10.4172/2329-6798.1000218

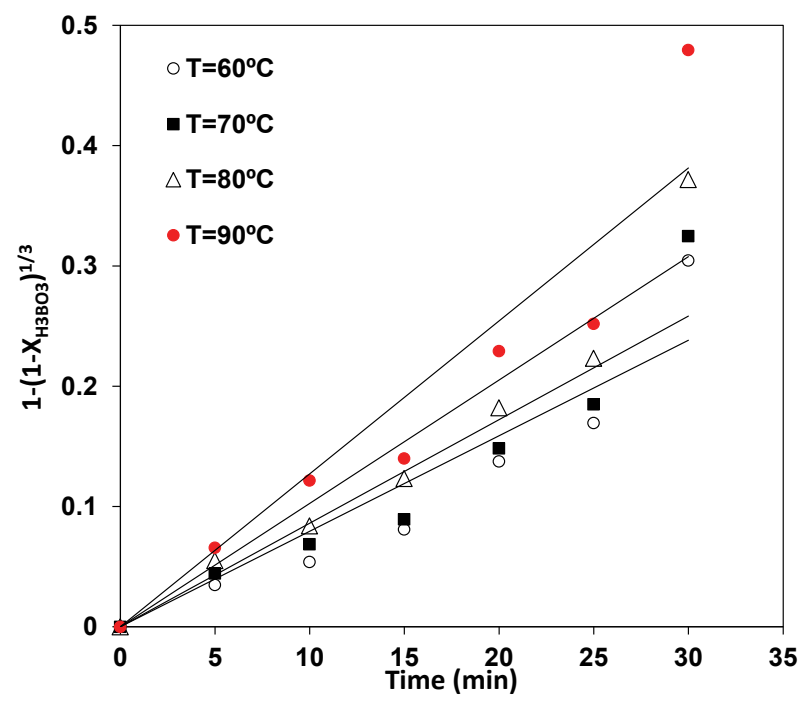

Figure 10: Plot of chemical system during the time at various temperatures.

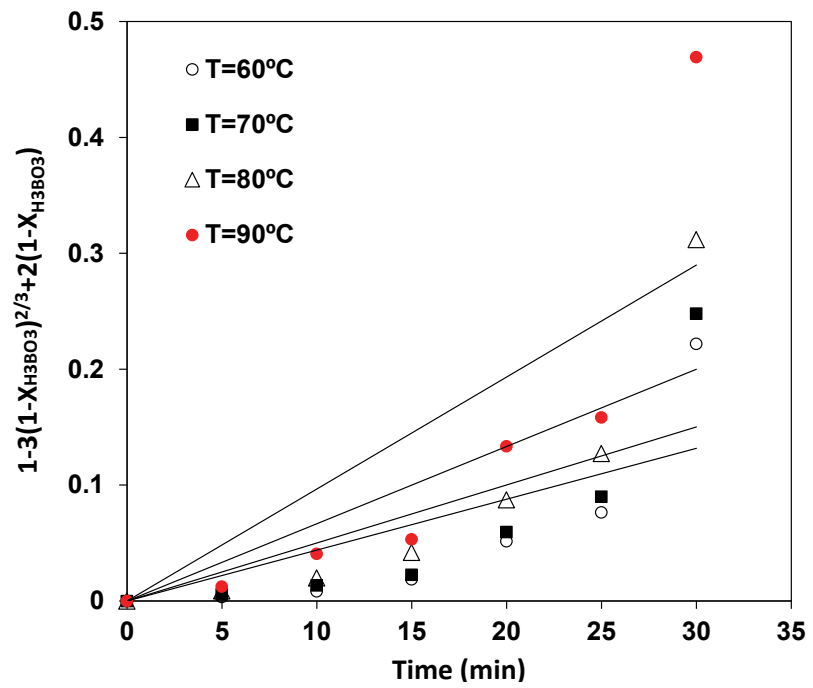

Figure 11: Plot of diffusion through a solid system during the time at various temperatures.

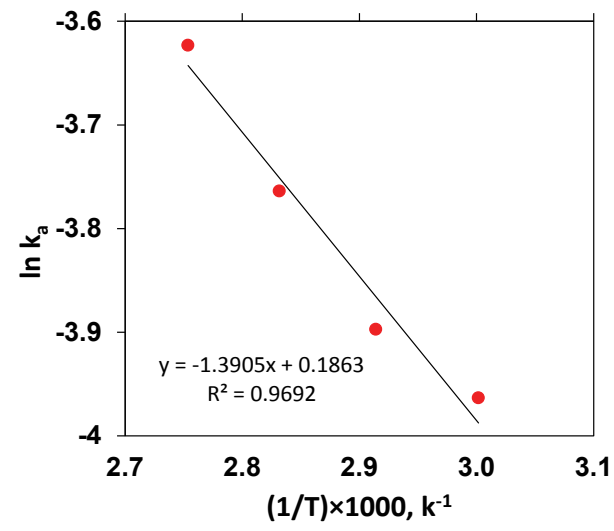

Figure 12: Arrhenius plot for leaching of Boron in the temperature range 333$364 \mathrm{~K}^{-1}$.

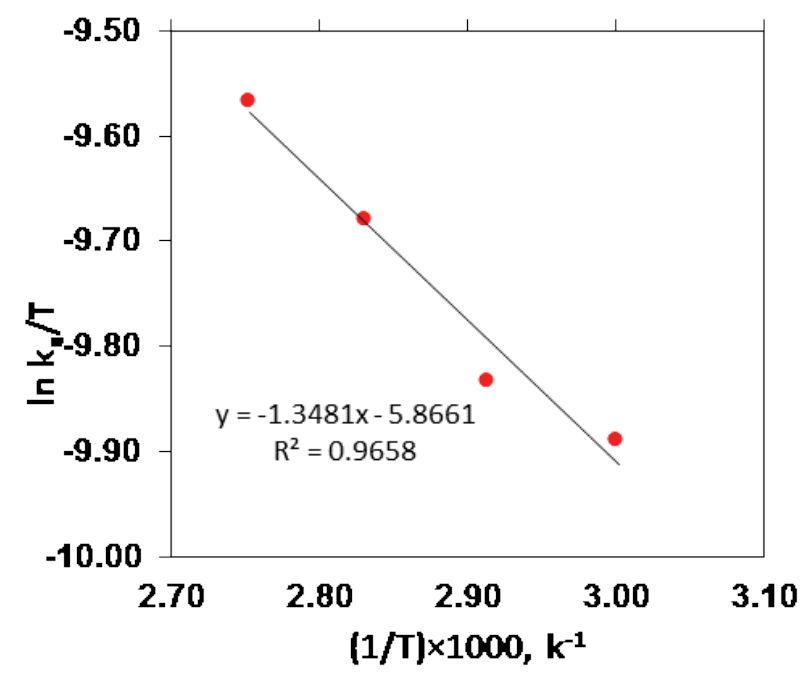

Figure 12.1: Arrhenius plot for leaching of Boron in the temperature range 333$364 \mathrm{~K}^{-1}$.

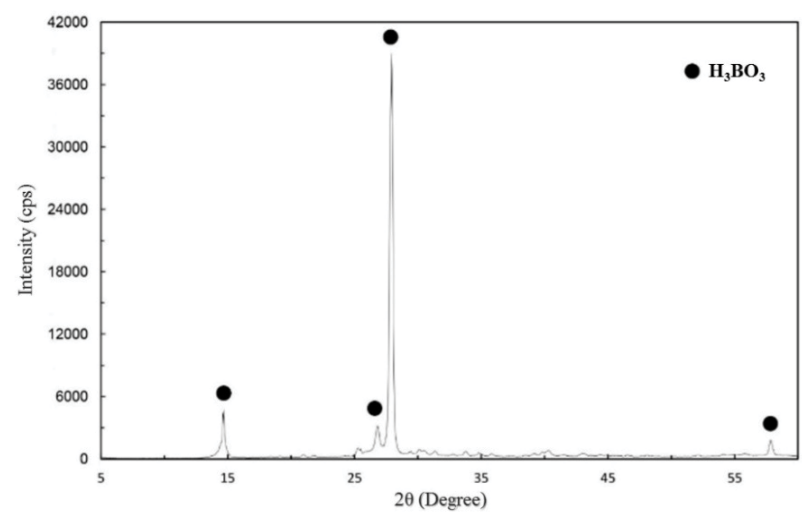

Figure 13: XRD analysis of product of Boric acid.

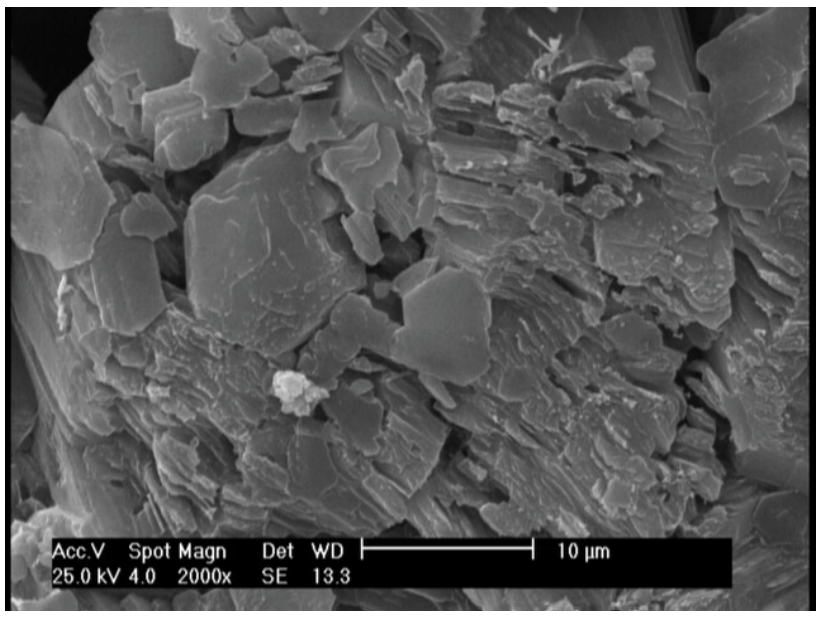

Figure 14: SEM micrograph of precipitated Boric acid sample.

Maximum Concentration of Contaminants for Toxicity Characteristic (United States Environmental Protection Agency and China GB/5085.32007). Finally, crystallization rate of boric acid can reach $99.74 \%$. 
Citation: Mahdi H, Davood M, Mohsen V, Behzad S (2017) Boric Acid Production from a Low-Grade Boron Ore with Kinetic Considerations. Mod Chem appl 5: 218. doi: 10.4172/2329-6798.1000218

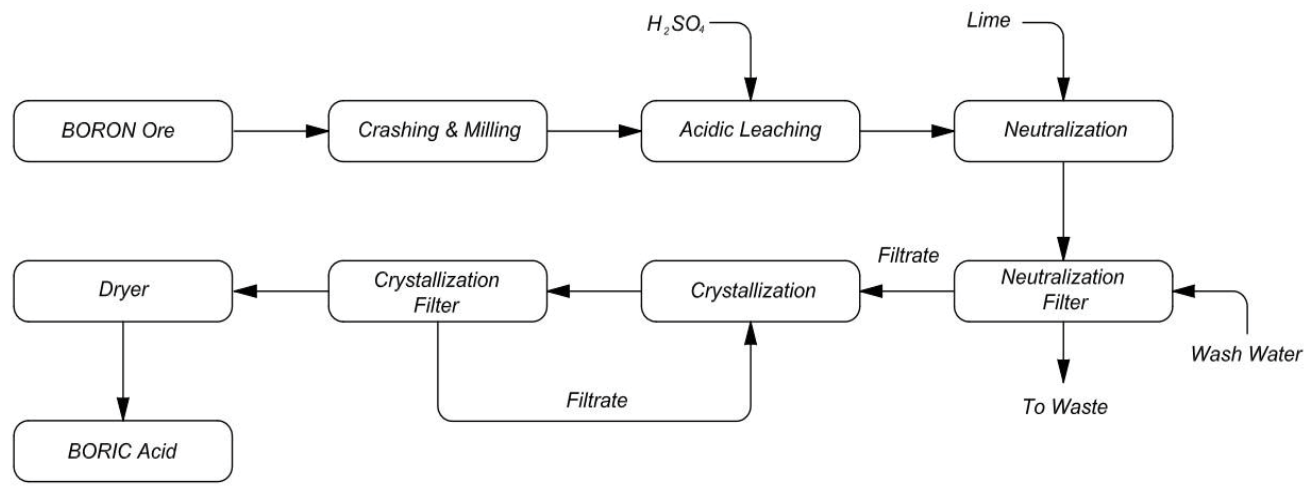

Figure 15: Working Flow Diagram for production of Boric acid.

\begin{tabular}{|c|c|c|c|}
\hline Temperature $\left({ }^{\circ} \mathrm{C}\right)$ & XB & $1-3(1-X B)^{2 / 3}+2(1-X B)$ & $1-(1-X B)^{1 / 3}$ \\
\hline 60 & 0.9454 & 0.6164 & 0.8776 \\
\hline 70 & 0.9558 & 0.6348 & 0.8898 \\
\hline 80 & 0.9796 & 0.6913 & 0.9237 \\
\hline 90 & 0.9626 & 0.6539 & 0.8835 \\
\hline
\end{tabular}

Table 3: The results of the $\mathrm{R}^{2}$ values for each model.

\begin{tabular}{|c|c|c|c|c|c|c|}
\hline Step/Condition & Solid (gr) & Value (L) & $\mathrm{B}_{2} \mathrm{O}_{5}(\%)$ & B (gr/L) & Mass Balance & stage recovery $\%$ \\
\hline 1. Feed & 10000 & - & 8.95 & - & - & - \\
\hline 2. Acidic Leach & - & - & - & - & 99.44 & 91.71 \\
\hline Solid & 9740 & - & 0.71 & - & - & - \\
\hline Filtrate & - & 26.3 & - & 6.64 & - & - \\
\hline 3. Neutralization & - & - & - & - & 99.52 & 99.45 \\
\hline Solid & 347 & - & 0.18 & - & - & - \\
\hline Filtrate & - & 26.8 & - & 6.48 & - & - \\
\hline 4. Crystallization & - & - & - & - & 99.23 & 75.28 \\
\hline Solid & 745.12 & - & 81.83 & - & - & - \\
\hline Filtrate & - & 26.3 & - & 1.62 & - & - \\
\hline 5. Product & 745.12 & & & & 98.30 & 90.50 \\
\hline
\end{tabular}

Table 4: Results of Scale-up experiment.

\section{Conclusions}

In this study, dissolution of boron ore sample with $\mathrm{H}_{2} \mathrm{SO}_{4}$ acid at various experimental conditions was examined and research findings obtained in this study are as follows. $\mathrm{pH}$ has a significant effect on extraction of boron from ore. As $\mathrm{pH}$ in leaching test increases, the extraction recoveries of sample tend to increase. An increase in reaction temperatures caused an increase in sample dissolved rate. Optimum condition for acidic leaching section was obtained in temperature of $90^{\circ} \mathrm{C}$, reaction time of 2 hours, $\mathrm{L} / \mathrm{S}$ ratio of 3 , and $\mathrm{pH}$ of 1 . In the optimum point, the recovery of boron acidic leaching was achieved $92.21 \%$. After precipitation of iron, boric acid was obtained by crystallization. Purity of produced boric acid was $99.56 \%$. Dissolution of boron ore was followed fluid film diffusion controlled reaction and the reaction activation energy was equaled to $11.6 \mathrm{~kJ} / \mathrm{mol}$. Enthalpy of activation $\left(\llbracket \Delta \mathrm{H} \rrbracket^{\wedge} \ddagger\right)$ and entropy of activation $\left(\llbracket \Delta S \rrbracket^{\wedge} \ddagger\right)$ were $11.2 \mathrm{~kJ} /$ $\mathrm{mol}$ and $-246.3 \mathrm{~J} /(\mathrm{mol} . \mathrm{K})$ respectively.

\section{Acknowledgements}

The authors are thankful to the Research and Engineering Co. for Non-Ferrous Metals for financial and technical support and the permission to publish this paper.

\section{References}

1. Tokatli C, Arslan EKN, Arzu OE (2016) Ecosystem Quality Assessment of an Aquatic Habitat in a Globally Important Boron Reserve: Emet Stream Basin (Turkey). Environment and Pollution 59: 116-141.

2. William HS, Vengosh $A$ (2016) Global boron cycle in the Anthropocene. Global Biogeochemical Cycles 30: 219-230.

3. Sert $\mathrm{H}$, Yildiran $\mathrm{H}$ (2011) A study on an alternative method for the production of boric acid from ulexite by using trona. Journal of Ore Dressing 13: 1.

4. Levent S, Pamuko Y, Gonen M (2016) Extraction of Boric Acid from Tincal Mineral by Supercritical Ethanol. The Journal of Supercritical Fluids 109: 67-73.

5. Onal G, Burat F (2008) Boron Mining and Processing in Turkey. Mineral Resources Management 24: 49-60.

6. Demircioglu A (2011) Boron Minerals of Turkey-Hydroboracite. Mineral Research and Exploration Institute of Turkey 543: 1-26.

7. Flores HR, Mattenella LE, Valdez SK (2002) Physical and physicochemical properties of borates from Argentine Puna. Technological Information 132: 103-108.

8. Mergen A, Demirhan MH, Bilen M (2003) Processing of Boric Acid from Borax by a Wet Chemical. Advanced Powder Technology 14: 279-293.

9. Kuskay B, Bulutcu AN (2011) Design Parameters of Boric Acid Production Process from Colemanite Ore in the Presence of Propionic Acid. Chemical Engineering and Processing 50: 377-383. 
Citation: Mahdi H, Davood M, Mohsen V, Behzad S (2017) Boric Acid Production from a Low-Grade Boron Ore with Kinetic Considerations. Mod Chem appl 5: 218. doi: 10.4172/2329-6798.1000218

Page 7 of 7

10. Tunc M, Kocakerim M, Yapici S (1999) Dissolution Mechanism of Ulexite in $\mathrm{H}_{2} \mathrm{SO}_{4}$ Solution. Hydrometallurgy 51: 359-370.

11. Kalafatoglu IE, Oes N, Ozdemir SS (2000) Dissolution behavior of colemanite with sulfuric acid. Proceedings of IV National Chemical Engineering Conference, Istanbul, Turkey, pp: 263-268.

12. Cetin E, Eroglu I, Ozkar S (2001) Kinetics of Gypsum Formation and Growth during the Dissolution of Colemanite in Sulfuric Acid. Journal of Crystal Growth 231: 559-567.
13. Gaye OC (2004) The Effect of Stirring Rate on Dissolution of Colemanite and Particle Size of Gypsum Crystals during the Boric Acid production in a Batch reactor. Ultaniyat Bor Symposium, Turkey 23: 319-325

14. Okur H, Tekin T, Ozer K, Bayramoglu M (2002) Effect of Ultrasound on the Dissolution of Colemanite in $\mathrm{H}_{2} \mathrm{SO}_{4}$. Hydrometallurgy 67: 79-86.

15. Levenspiel O (1999) Chemical reaction engineering. Industrial \& engineering chemistry research. ACS Publications 38: 4140-4143.

16. Xuin GH, Yu D, Su Y (1986) Leaching of scheelite by hydrochloric acid in the presence of phosphate. Hydrometallurgy 16: 27-40.

17. Pohlman SL, Olson FA (1974) A kinetic study of acid leaching of chrysocolla using a weight loss technique. Solution Mining Symposium, AIME. 